\title{
Influência da inclinação do eixo de rotação da Terra na temperatura do ar global
}

\section{Influence of the inclination of Earth's rotation's axis in the global air temperature}

\author{
Michelle Simões Reboita, Angelita de Paula Pimenta e Ulisses Antônio Natividade \\ Instituto de Recursos Naturais, Universidade Federal de Itajubá (Unifei). Av. BPS, 1303, bairro Pinheirinho, CEP 37500-903, Itajubá - MG \\ reboita@unifei.edu.br
}

\author{
Manuscrito: \\ Recebido: 24/04/2014 \\ Corrigido: $18 / 04 / 2015$ \\ Aceito: 23/04/2015
}

Citation: Reboita M.S., Pimenta A.P. e Natividade U.A. 2015. Influência da inclinação do eixo de rotação da terra na temperatura do ar global. Terræ Didatica, 11(2):67-77. <http://www.ige.unicamp.br/terraedidatica/>.

Keywords: Milankovitch's orbital parameters, Earth, numeric simulations, climate
ABSTRACT: The Earth's climate is controlled by external and internal forcings of the terrestrial system. Among external forcings we have Milankovitch's orbital parameter: eccentricity, precession and obliquity. As the definition of these parameters and their influence on Earth's climate are addressed superficially in textbooks in high school and even in college, this study has two purposes: (1) to present an explanation of each Milankovitch's orbital parameter and as the Earth's climate is affected by these parameters and (2) to evaluate the results of numeric simulations on the globe where the inclination angle of the rotation's axis of the Earth is changed. It is shown that than greater the obliquity of Earth's rotation's axis, the range of the greatest heating during the summer of a given hemisphere moves to higher latitudes.

\section{Introdução}

O clima da Terra é controlado tanto por forçantes externas quanto internas ao sistema terrestre. As forçantes externas são aquelas que influenciam o clima, porém não são afetadas por ele, como: as variações na constante solar e na órbita da Terra ao redor do Sol, as erupções vulcânicas e a deriva continental. Por outro lado, as forçantes internas são aquelas que influenciam o clima e são afetadas por ele (há um processo de retroalimentação), tais como os oceanos e os processos ocorridos na interface superfície-atmosfera (Hartmann 1994).

Com relação aos fatores externos, Milutin Milankovitch foi um dos pesquisadores preocupados com o entendimento da influência dos parâmetros orbitais da Terra no clima do planeta. Ele começou seu trabalho em 1911 a fim de determinar os parâmetros orbitais que justificavam a variação latitudinal e sazonal da radiação solar recebida na superfície terrestre (Hartmann 1994). Assim, identificou a excentricidade da órbita da Terra, a obliquidade do eixo de rotação do planeta e a precessão (que se tornaram conhecidos como parâmetros orbitais de Milankovitch) como fatores que modificariam a insolação nas diferentes latitudes (Moran 2012). De acordo com diferentes autores (Hartmann 1994, Ruddiman 2008, Moran 2012), as variações nos parâmetros orbitais de Milankovitch não alteram significativamente o total anual da energia solar recebida no planeta, porém elas modificam a radiação solar recebida por latitude e estação do ano. Por exemplo, a combinação dos três parâmetros orbitais pode fazer com que a insolação seja reduzida num dos hemisférios (norte ou sul) tornando os verões mais brandos ou intensificando os invernos. Esse exemplo ficará mais claro após a explicação dos três parâmetros orbitais dada na seção 2 . 
Os parâmetros orbitais de Milankovitch é um assunto abordado de forma superficial nos livros-texto do ensino médio e até nos do superior. Em geral é mencionado que os parâmetros orbitais de Milankovitch causam influências no clima terrestre, mas sem discutir o real efeito desses parâmetros. Assim, o presente estudo tem dois objetivos: (1) explicar cada parâmetro orbital de Milankovitch e como o clima da Terra é afetado por esses parâmetros e (2) avaliar, por meio de simulações numéricas, a influência do ângulo de inclinação do eixo de rotação da Terra na distribuição espacial e sazonal da temperatura do ar global, já que esse é o principal fator que controla o ciclo anual da temperatura do ar nas diferentes latitudes do planeta. Esse estudo está organizado da seguinte forma: a seção 2 apresenta a descrição dos parâmetros orbitais de Milankovitch e como eles influenciam o clima da Terra; a seção 3 mostra a metodologia do estudo; a seção 4 apresenta os resultados das simulações numéricas; e a seção 5 as conclusões finais.

\section{Parâmetros Orbitais de Milankovitch}

\subsection{Excentricidade}

A excentricidade da Terra indica o quanto a órbita da Terra se desvia de um círculo, isto é, o quanto ela se torna mais elíptica. Quando a órbita é circular, o Sol encontra-se no centro do círculo; quando a órbita é elíptica, ele se localiza num dos focos (Fig. 1). Nesse último caso, ao longo de um ciclo de translação, a Terra passará por um ponto mais próximo do Sol (periélio) e por um ponto mais distante (afélio). Atualmente, há uma diferença de 3,3\% na distância Terra-Sol entre o afélio e o periélio (Moran 2012), o que faz com que o topo da atmosfera intercepte cerca de $6,7 \%$ mais radiação solar no periélio do que no afélio. Como, atualmente, o periélio ocorre em 3 de janeiro e o afélio em 4 de julho, nota-se que o afélio corresponde ao período de verão boreal. Assim, poder-se-ia pensar que ambos os hemisférios vivenciaram um período mais frio em julho, mas isso não ocorre porque os $6,7 \%$ de menos energia não é suficiente para deixar o planeta frio. Hartmann (1994) menciona que a dependência da insolação anual na excentricidade é muito fraca, sendo que a variação anual da insolação obtida entre uma órbita circular a uma mais elíptica (com excentricidade de cerca de 0,06 ) é de apenas $\sim 0,18 \%$. A excentricidade da órbita da

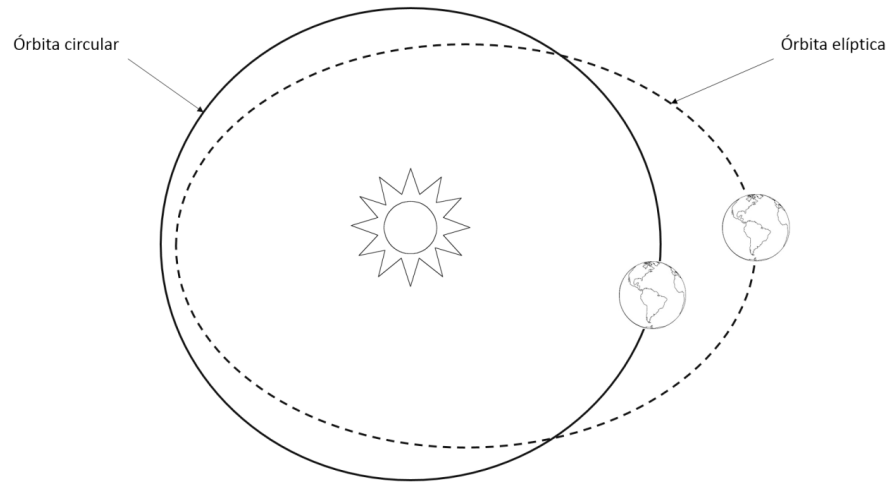

Figura 1. Exemplo de uma órbita circular (linha contínua) e de uma órbita elíptica (linha tracejada ). $\mathrm{Na}$ órbita elíptica o Sol se encontra num dos focos da elipse, ou seja, não se localiza no centro como na órbita circular.

Terra ao redor do Sol varia de elíptica para quase circular em ciclos irregulares de 90.000 a 100.000 anos (Moran 2012). O valor atual da excentricidade do planeta é de 0,0167 (Ruddiman 2008).

\subsection{Precessão}

O efeito da precessão do eixo de rotação da Terra pode ser comparado ao efeito de um pião: assim como o pião gira em torno de si e seu eixo bamboleia descrevendo um movimento em torno de uma elipse (Fig. 2), a Terra também. Esse efeito ocorre devido às forças diferencias do Sol e da Lua sobre a Terra (Ruddiman 2008, Oliveira Filho e Saraiva 2014). A precessão não corresponde a uma variação na inclinação do eixo da Terra, mas sim uma alteração na orientação desse eixo em torno da órbita do planeta (Fig. 3). Portanto, a precessão é responsável por alterar a posição que a Terra ocupa na elipse na ocorrência dos equinócios e solstícios. Em outras palavras, hoje o verão no Hemisfério Sul (HS) inicia em dezembro e é nessa estação que também ocorre o periélio (3 de janeiro), já a cerca de 11.000 anos atrás o verão austral também iniciava em dezembro, mas quando a Terra estava no seu ponto mais afastado do Sol, ou seja, no afélio (Fig. 3). A mesma ideia é aplicada para o Hemisfério Norte (HN), ou seja, o verão boreal atualmente inicia em junho e nessa estação ocorre o afélio (4 de julho); há cerca de 11.000 anos atrás o verão do HN também iniciava em junho, mas quando a Terra estava na posição orbital mais perto do Sol, no periélio (Fig. 3). O ciclo da precessão dos equinócios é de cerca de 23.000 anos (Ruddiman 2008). 


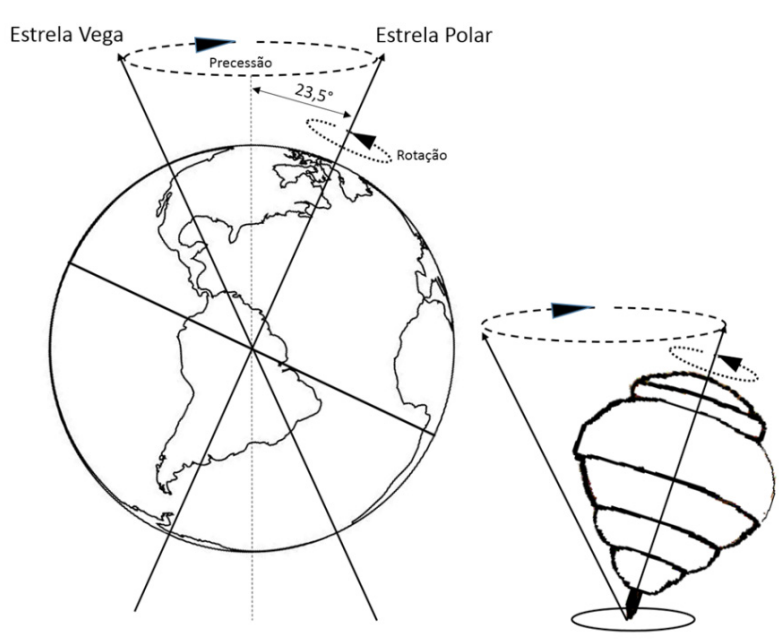

Figura 2. Exemplo ilustrativo do efeito de precessão. Assim como um pião gira em torno de si e seu eixo bamboleia descrevendo um movimento em torno de uma elipse, a Terra também o faz.

\subsection{Obliquidade}

Como as variações na média anual da insolação associadas com as modificações na excentricidade da órbita da Terra são muito pequenas para produzir mudanças significativas no clima, Milankovitch pensou numa explicação para as idades do gelo associadas com a inclinação do eixo de rotação da Terra: a insolação em altas latitudes no verão num determinado hemisfério será maior quanto maior for a inclinação do eixo de rotação da Terra (que é no máximo de $24,5^{\circ}$ ). Além disso, a insolação será maior se o solstício de verão ocorrer no periélio. Portanto, condições mais frias ocorrerão no outro hemisfério contribuindo para um inverno mais rigoroso.

A obliquidade (inclinação) do eixo de rotação da Terra em relação ao seu plano orbital (Fig. 4) é o fator de maior importância para o ciclo anual da temperatura do ar nas diferentes bandas de latitude do planeta (Hartmann 1994). Se a obliquidade for zero, a média anual da insolação nos polos também é zero. Porém, quanto maior for a obliquidade, maior será a variação da insolação entre as latitudes altas e os trópicos. Spiegel et al. (2009) e Ferreira et al. (2014) mencionam que obliquidades maiores ou iguais a $54^{\circ}$ produzem uma inversão horizontal de temperatura em relação ao clima atual. Como os polos tornam-se mais quentes do que os trópicos, há uma inversão na circulação global, uma vez que os gradientes de temperatura passam a apontar dos trópicos para os polos (das menores para as maiores temperaturas).

A obliquidade do eixo de rotação é praticamente estável, pois oscila apenas entre $22,1^{\circ}$ a $24,5^{\circ}$, em períodos de cerca de 41.000 anos (o valor atual da obliquidade é $23,5^{\circ}$ ), e essa estabilidade é mantida pelo torque exercido pela Lua (Laskar et al. 1993). De acordo com Hartmann (1994), as variações na obliquidade dentro do intervalo angular mencionado podem produzir alterações de cerca de $10 \%$ na insolação em latitudes altas.

Unificando os conhecimentos de Milankovitch em relação aos três parâmetros orbitais, nota-se
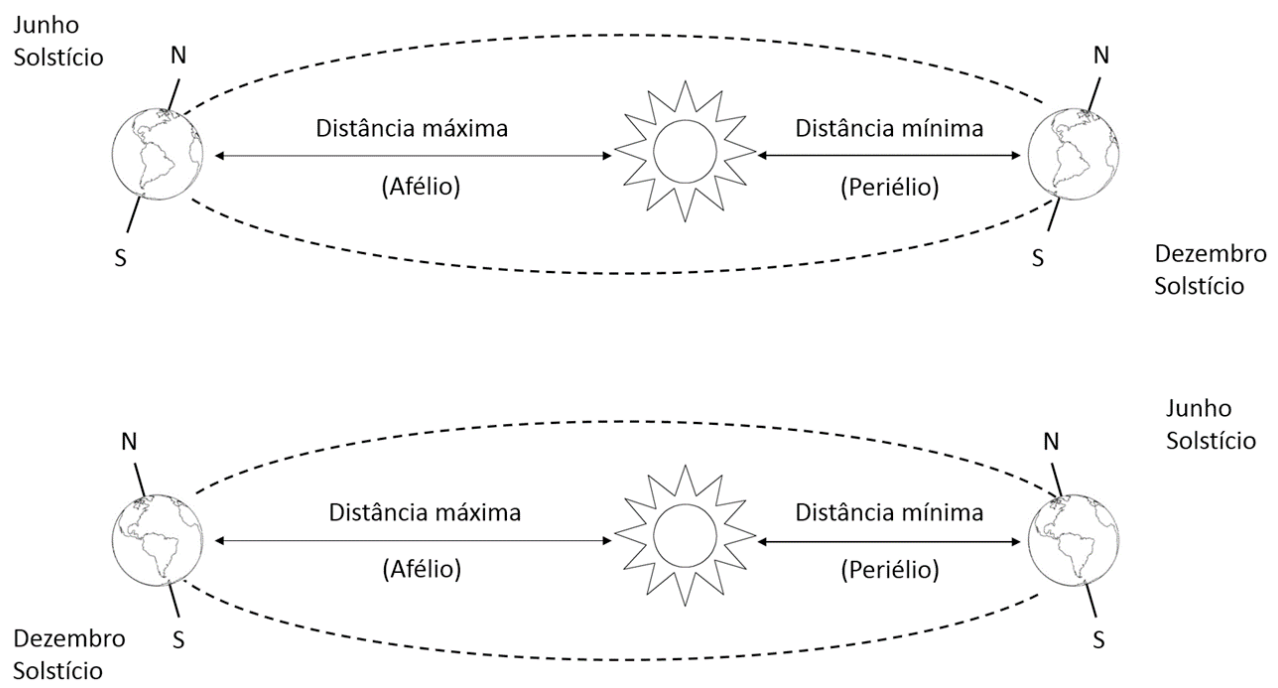

Figura 3. Mudança na data de ocorrência do periélio e afélio devido ao efeito da precessão. 0 painel superior mostra a situação atual com o periélio ocorrendo concomitantemente com o verão no Hemisfério Sul. Já o painel inferior é um caso de milhares de anos atrás, quando o periélio ocorria concomitantemente com o solstício de verão no Hemisfério Norte. Nos dois painéis não está sendo considerada a mudança na excentricidade da órbita terrestre. Adaptado de Ruddiman (2008). 


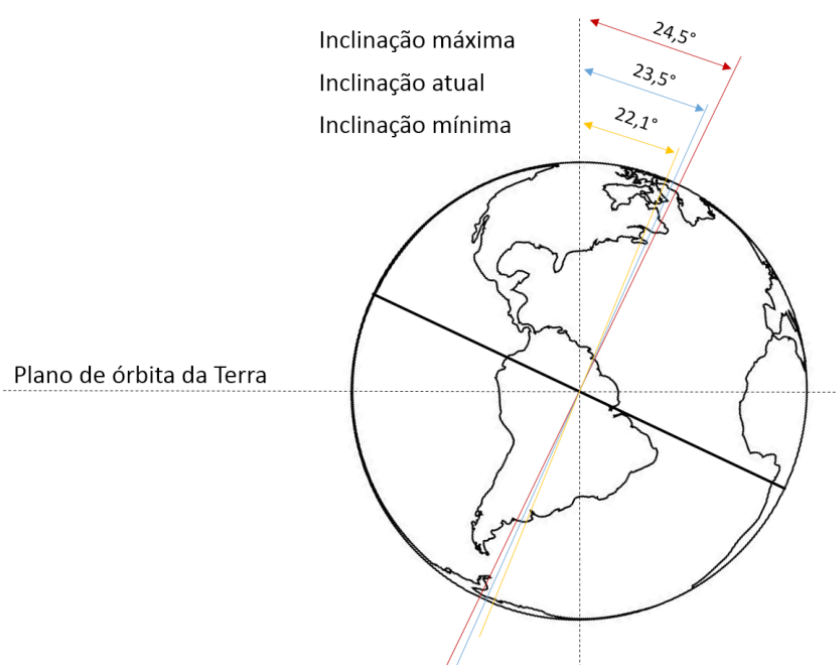

Figura 4. Obliquidade (inclinação) do eixo de rotação da Terra em relação ao seu plano orbital.

que a junção deles pode influenciar sazonalmente a energia solar recebida nas diferentes bandas de latitude do planeta. Se for considerada, por exemplo, uma situação em que a Terra está com sua inclinação máxima do eixo de rotação em relação ao plano orbital $\left(24,5^{\circ}\right)$, que o periélio ocorre em janeiro concomitantemente com o solstício de verão no Hemisfério Sul e que a Terra está com sua máxima excentricidade (o que reduz a distância Terra-Sol no periélio), isso leva a um maior aquecimento nas latitudes altas do Hemisfério Sul e um resfriamento nas latitudes altas do Hemisfério Norte. Como menciona Hartmann (1994), o efeito combinado dos três parâmetros orbitais pode causar variações de cerca de 30\% na insolação sazonal em latitudes altas.

Tendo em vista que a inclinação do eixo de rotação da Terra em relação ao seu plano orbital é o principal fator que controla o ciclo anual da temperatura do ar nas diferentes latitudes do planeta, a seção 4 irá mostrar resultados de simulações em que o ângulo de inclinação do eixo de rotação da Terra foi modificado a fim de se verificar o impacto desse parâmetro orbital na temperatura do ar do planeta. Mapas mostrando tais impactos facilitam a compreensão do parâmetro obliquidade pelos estudantes de nível médio.

\section{Metodologia}

\subsection{EdGCM}

Foram realizadas simulações com o Educational Global Climate Model (EdGCM), versão 3.2.1. O EdGCM é um modelo desenvolvido pela National Aeronautics and Space Administration (NASA) para fins educacionais. Esse modelo é baseado no NASA Goddard Institute for Space Studies' Global Climate Model II (GISS GCM II; Hansen et al. 1983), que é um modelo tri-dimensional com resolução horizontal de $8^{\circ}$ de latitude por $10^{\circ}$ de longitude, nove camadas verticais (com topo em $10 \mathrm{mb}$ ) e com duas camadas no solo para resolver processos hidrológicos. Partículas de nuvens, aerossóis e gases (tais como: dióxido de carbono, metano e óxido de nitrogênio) são incorporados explicitamente no esquema de radiação. Nesse modelo, a precipitação é gerada quando há condições de supersaturação. A temperatura da superfície do mar é determinada usando um modelo derivado de fluxos de energia na superfície e de convergência de calor no oceano pré-especificados.

As condições de fronteira geográfica (topografia e vegetação) estão fixas no modelo, não permitindo modificação pelo usuário. O modelo também já inclui as variáveis atmosféricas usadas como condição inicial das simulações. Como o EdGCMé um modelo educacional, ele pode ser instalado em várias plataformas e possui uma interface gráfica. Nessa, o usuário só precisa definir os parâmetros de suas simulações, tais como: período, concentração de gases atmosféricos, luminosidade solar, parâmetros orbitais etc.

\subsection{Características das Simulações}

Para avaliar a influência da inclinação do eixo de rotação da Terra na temperatura do ar do planeta, foram realizadas cinco simulações no período de 1940 a 2010. A simulação controle considera o ângulo (em graus) de inclinação do eixo de rotação da Terra previamente especificado no modelo $\left(23,5^{\circ}\right)$, enquanto as demais tiveram o ângulo de inclinação alterados (Tab. 1).

Após realizadas as simulações, calcularam-se as médias climáticas sazonais (para o verão e inverno

Tabela1 Obliquidade utilizada em cada simulação climática.

\begin{tabular}{c|c}
\hline Simulação & Valor da inclinação \\
\hline Controle & $23,5^{\circ}$ \\
Inclinação zero & $0^{\circ}$ \\
Inclinação $15^{\circ}$ & $15^{\circ}$ \\
Inclinação $30^{\circ}$ & $30^{\circ}$ \\
Inclinação 45 & $45^{\circ}$ \\
\hline
\end{tabular}


austral) e anual da temperatura do ar. Na sequência, foram computadas as diferenças entre cada simulação em relação à controle. Essa etapa de pós-processamento das simulações foi executada com o software EVA (EdGCM Visualization Application).

\section{Resultados}

Como visto anteriormente, a inclinação do eixo de rotação da Terra em relação ao seu plano orbital é o parâmetro de Milankovitch de maior importância para o ciclo anual da temperatura do ar nas diversas latitudes do planeta. Quanto maior a inclinação do eixo de rotação, maior será o aquecimento em latitudes altas. Entretanto, é importante salientar que a resposta climática também é influenciada pelo tamanho e forma dos continentes em função da diferença de capacidade térmica destes em relação aos oceanos, pelo tipo de cobertura da superfície a qual irá influenciar o albedo e pela topografia, uma vez que regiões mais elevadas são mais frias.

A Fig. 5 mostra a média anual (janeiro a dezembro) da temperatura do ar próxima à superfície simulada considerando diferentes ângulos de inclinação do eixo de rotação da Terra. Há um padrão espacial similar nas simulações com eixo inclinado em $0^{\circ}, 15^{\circ}, 23,5^{\circ}$ e $30^{\circ}$, isto é, as temperaturas decrescem da região tropical para os polos em ambos os hemisférios. Já a diferença notada nas quatro simulações é que as temperaturas mais elevadas são mais concentradas na região tropical quanto menor o ângulo de inclinação do eixo de rotação da Terra. De fato, no experimento $0^{\circ}$, como os raios solares estão sempre perpendiculares ao equador ao longo do ano, as maiores temperaturas ocorrem nessa região e as menores nos polos (Fig. 5a). Com o aumento do ângulo de inclinação do eixo de rotação da Terra (Figs. 5b-d), os solstícios, ao longo do ano, migram latitudinalmente em direção aos polos implicando no deslocamento das regiões com maior aquecimento, o que diminui a diferença de temperatura entre polos e equador. No experimento em que o eixo de rotação da Terra foi inclinado em $45^{\circ}$ (Fig. 5d), como os solstícios ocorrem em maiores latitudes do que nas demais simulações, isso causa um aquecimento mais homogêneo do planeta em ambos os hemisférios. Em geral, os oceanos são mais quentes entre $60^{\circ} \mathrm{S}$ e N (excluindo a região equatorial) do que os polos e as áreas continentais (Fig. 5d). Provavelmente, o maior aquecimento dos oceanos está associado à maior capacidade térmica da água do que a da terra.
Uma característica importante nos experimentos $0^{\circ}, 15^{\circ}, 23,5^{\circ}$ e $30^{\circ}$ (Figs. 5 a-b-c-e) é que o aquecimento na região tropical não ocorre de maneira simétrica em ambos os hemisférios; no $\mathrm{HN}$ a área mais quente é ligeiramente mais extensa latitudinalmente e, segundo Feulner et al. (2013), isso torna o $\mathrm{HN}$ entre $1^{\circ}$ a $2^{\circ} \mathrm{C}$ mais quente do que o HS na média anual. Feulner et al. (2013) e Kang et al. (2015) mencionam que historicamente as diferenças de temperatura entre os hemisférios norte e sul têm sido atribuídas há vários fatores, como: ao $\mathrm{HN}$ ter mais área continental e, portanto, se aquecer mais no verão devido à menor capacidade térmica em relação ao oceano e pelo transporte de calor dos oceanos austrais para o HN. Ambos, Feulner et al. (2013) e Kang et al. (2015) fizeram estudos com modelos numéricos e mostraram a importância do transporte meridional de calor nos oceanos do HS para o HN como principal causa das diferenças de temperatura inter-hemisféricas. Entretanto, Feulner et al. (2013) também mencionam uma contribuição adicional da diferença de albedo entre as regiões polares. Já para Kang et al. (2015), a contribuição adicional seria a diferença no aprisionamento dos gases de efeito estufa em ambos os hemisférios. Isso seria provavelmente o resultado de como o arranjo dos continentes e o impacto desses sobre a circulação oceano-atmosfera (como as monções, anticiclones subtropicais e regiões de ressurgência no oceano) determinam a distribuição de vapor d'água na atmosfera. Os autores ainda mencionam que estudos adicionais precisam ser realizados sobre esse tema. Pelo fato do HN ser mais quente do que o HS, o equador térmico localiza-se a cerca de $10^{\circ} \mathrm{N}$ enquanto o equador geográfico em $0^{\circ}$. Outro fato interessante na Fig. 5 é que nos cinco experimentos as temperaturas na Antártida são mais frias do que nas mesmas latitudes do HN, o que é decorrente da topografia ser mais elevada na Antártida (Feulner et al. 2013). A Fig. 5d mostra claramente outras regiões que apresentam menor temperatura em função da topografia elevada: Groelândia, Montanhas Rochosas (América do Norte), os Himalaias (Ásia) e a Cordilheira dos Andes (América do Sul).

Considerando-se o campo da diferença da média anual da temperatura do ar dos experimentos em relação ao controle, no experimento $0^{\circ}$, como ao longo do ano os raios solares estão sempre perpendiculares ao equador, as temperaturas nessa região serão mais elevadas do que no experimento controle (condição atual do planeta); o que implica 

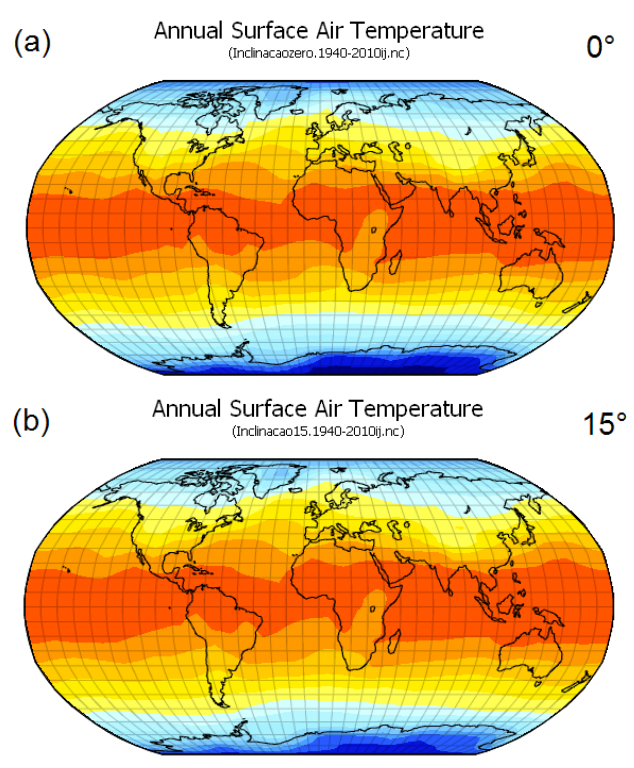

(c) Annual Surface Air Temperature $30^{\circ}$

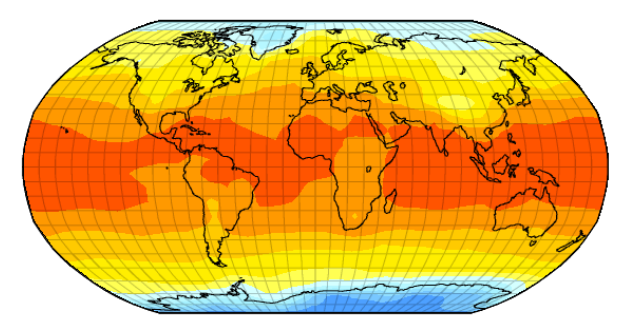

(d)

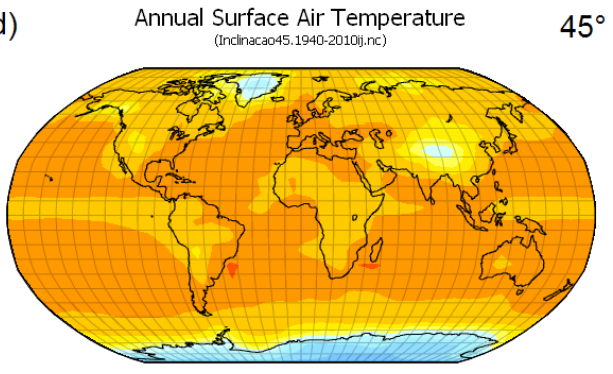

(e)

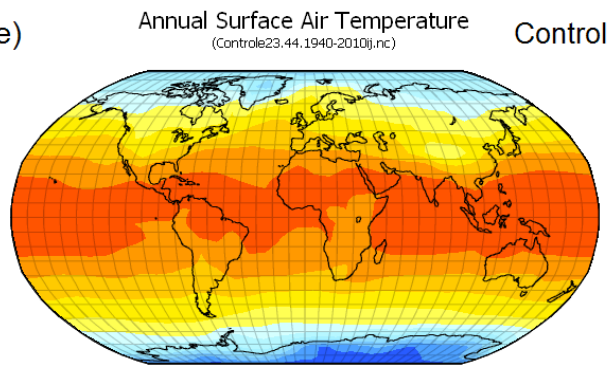

Surface Air Temperature (deg C)

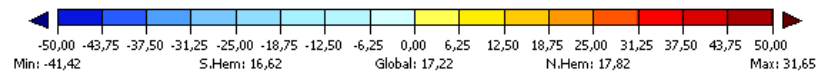

Figura 5. Média anual da temperatura do $\operatorname{ar}\left({ }^{\circ} \mathrm{C}\right)$ próxima à superfície no período de 1940 a 2010 considerando diferentes ângulos de inclinação do eixo de rotação da Terra. 0 valor do ângulo considerado em cada simulação aparece no canto superior direito de cada quadro diferenças positivas de temperatura do ar. Já nas demais latitudes do experimento $0^{\circ}$, as temperaturas são mais frias e, portanto, as diferenças são negativas (Fig. 6a). O campo espacial das diferenças de temperatura do ar no experimento $15^{\circ}$ em relação ao controle é similar ao obtido no experimento de $0^{\circ}$, pois o ângulo de inclinação de $15^{\circ}$ também permite um maior aquecimento na região próxima ao equador (Fig. 6b). Já os experimentos com ângulo de inclinação de $30^{\circ}$ e $45^{\circ}$ (Figs. 6 c-d), comparados ao controle, apresentam diferenças positivas de temperatura do ar nos extratrópicos e negativas nos trópicos. Em ambos os experimentos, os solstícios ocorrem em latitudes maiores do que na situação atual do planeta $\left(23,5^{\circ}\right)$, propiciando o maior aquecimento de tais latitudes.

Considerando o experimento com ângulo de $45^{\circ}$ (Fig. $5 \mathrm{~d}$ ), as temperaturas negativas na média anual só ocorrem sobre a Antártida, Groelândia e nos Himalaias (centro-sul da Ásia), onde há influência da topografia. Em termos da diferença desse experimento em relação ao controle (Fig. 6d), as latitudes médias e os polos em ambos os hemisférios possuem diferenças positivas de temperatura do ar, enquanto a região tropical apresenta diferenças negativas. Como mostrado por Williams e Pollard (2003), Spiegel et al. (2009) e Ferreira et al. (2014), na situação em que o planeta está inclinado em $23,5^{\circ}$, a radiação solar $\left(\mathrm{W} / \mathrm{m}^{-2}\right)$ é maior (mais concentrada e com maior tempo de duração diária) na região tropical e menor nos polos. À medida que a inclinação do eixo de rotação da Terra aumenta, há uma inversão nesse padrão de forma que com um ângulo de $90^{\circ}$ os polos recebem mais radiação do que os trópicos (exemplo Ward 1974). Essa radiação atmosférica elevada nos polos aquece a superfície o suficiente, evitando o acúmulo de neve e derretendo as capas de gelo que cobrem a Groelândia e Antártida no clima atual. Com o desaparecimento da neve e do gelo em altas latitudes, há o enfraquecimento do albedo planetário e, consequentemente, elevação das temperaturas médias anuais. Já nos trópicos, as temperaturas são inferiores às da atualidade devido ao menor tempo de insolação. Como destacam Williams e Pollard (2003), o aquecimento no verão em ambos os hemisférios consegue manter a superfície e a atmosfera quente durante os meses escuros de inverno. Portanto, isso justifica as diferenças positivas na temperatura do ar mostradas em latitudes médias e altas nos experimentos de $30^{\circ}$ e $45^{\circ} \mathrm{em}$ relação ao de $23,5^{\circ}$ (Figs. 6 c-d). 
(a)

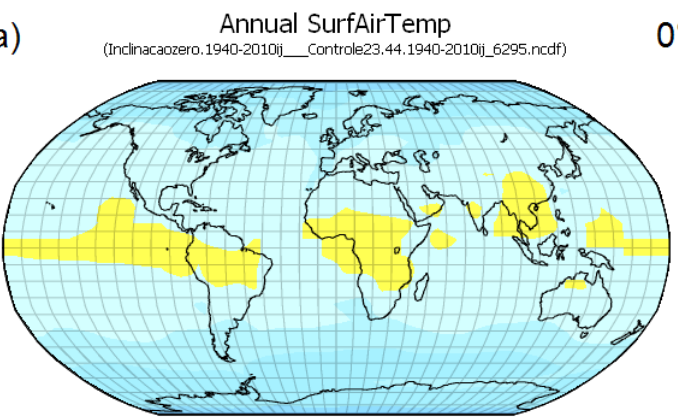

(b)

Annual SurfAirTemp (Inclinaca015.1940-2010ij_Controle23.44.1940-2010ij_6421.ncdf)

$15^{\circ}$

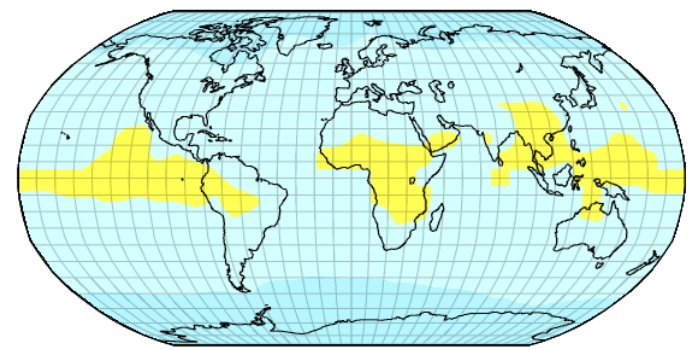

(c) Annual SurfAirTemp

$30^{\circ}$

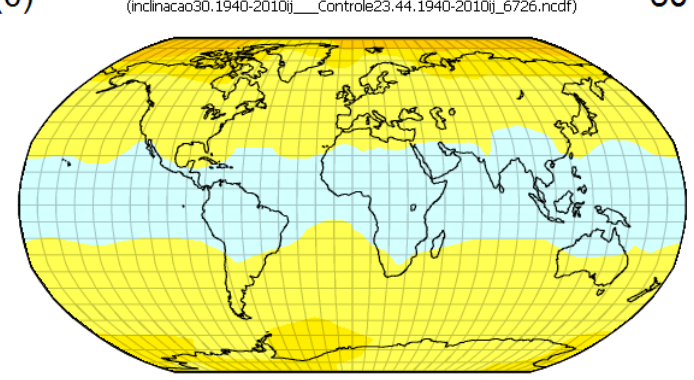

(d)

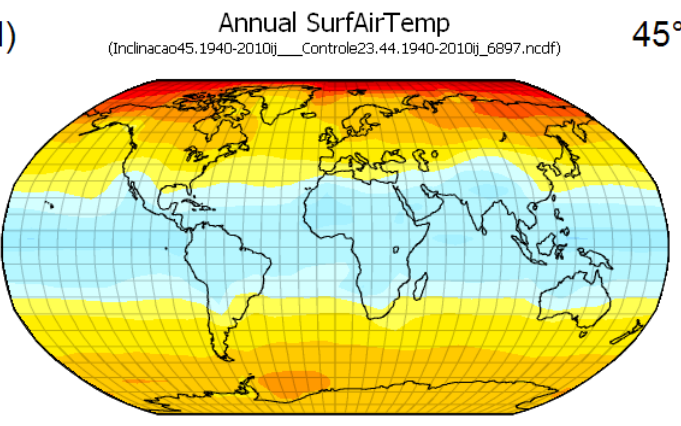

SurfAirTemp (deg C)

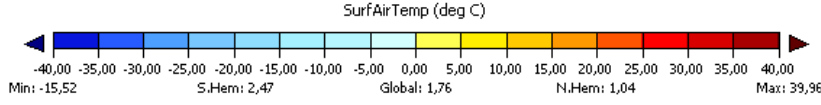

Figura 6. Diferença da temperatura do $\operatorname{ar}\left({ }^{\circ} \mathrm{C}\right)$ média anual entre os experimentos com ângulos de $0^{\circ}, 15^{\circ}, 30^{\circ}$ e 45 o em relação ao experimento controle $\left(23,5^{\circ}\right)$.

A Fig. 7 mostra a média da temperatura do ar próxima à superfície simulada no verão austral (dezembro, janeiro e fevereiro) considerando diferentes ângulos de inclinação do eixo de rotação da Terra. Na situação em que o eixo de rotação do planeta não possui inclinação (Fig. 7a), o padrão espacial das temperaturas é igual ao da média anual (Fig. 7a), onde os máximos de temperatura no verão ocorrem na região tropical (e com uma maior extensão latitudinal no HN como discutido anteriormente), e há uma redução das temperaturas em direção aos polos em ambos os hemisférios. À medida que o ângulo de inclinação do eixo de rotação da Terra aumenta, a faixa de maior aquecimento durante o verão austral deslocase para latitudes mais altas do HS. Com isso, as latitudes boreais tornam-se mais frias. Considerando-se uma inclinação de $45^{\circ}$ (Fig. 7 d), o máximo aquecimento no verão austral ocorre nas cercanias de $35^{\circ}$ S. Outra informação extraída da Fig. 7 é que, durante o verão austral, as temperaturas do ar são menores no interior dos continentes no $\mathrm{HN}$ do que nos oceanos na mesma latitude. Essas variações de temperatura do ar podem ser atribuídas ao aquecimento diferenciado entre o continente e o oceano: a capacidade térmica dos continentes é menor do que a dos oceanos, por isso, eles têm maior variação de temperatura (os continentes se resfriam e se aquecem mais rápido do que os oceanos). Além disso, a energia solar que chega sobre o continente é só absorvida por uma fina camada, o que também permite o rápido aquecimento, já no oceano ela penetra até maiores profundidades.

Com relação à diferença da temperatura do ar no verão austral dos experimentos em relação ao controle (Fig. 8), se a Terra não fosse obliqua em relação ao seu plano orbital, durante o verão austral o HN seria mais quente do que é na atualidade, enquanto o HS seria mais frio (Fig. 8a). Quando o ângulo de inclinação é maior do que o valor atual (Figs. $8 \mathrm{c}$-d), os raios solares tornam-se perpendiculares a áreas de maiores latitudes no HS e, dessa forma, há um maior aquecimento de tais latitudes. Entretanto, as diferenças de temperatura do ar são positivas nas latitudes médias e altas de ambos os hemisférios e negativas na região tropical. As diferenças positivas no HN são decorrentes do grande armazenamento de energia durante o verão boreal, que é importante para manter a superfície e a atmosfera aquecidas nos meses de inverno do HN. Além disso, quando a obliquidade da Terra é alta, o derretimento da neve e das capas de gelo no polo contribuem para diminuírem o albedo e, consequentemente, para o aumento das temperaturas (Williams e Pollard 2003). Uma vez que é verão austral, seriam esperados maiores diferenças positivas de temperatura do ar na região polar do HS do 
(a)

a) DecJanFeb Surface Air Temperature

$0^{\circ}$

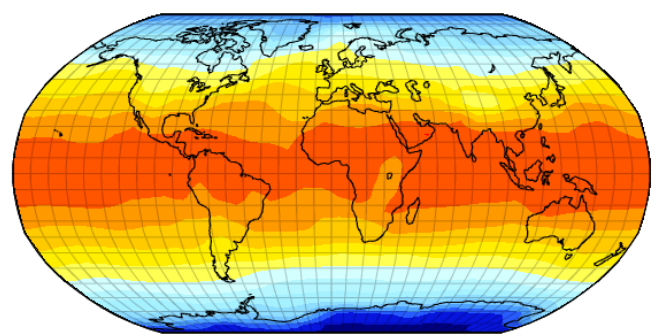

(b)

DecJanFeb Surface Air Temperature

$15^{\circ}$

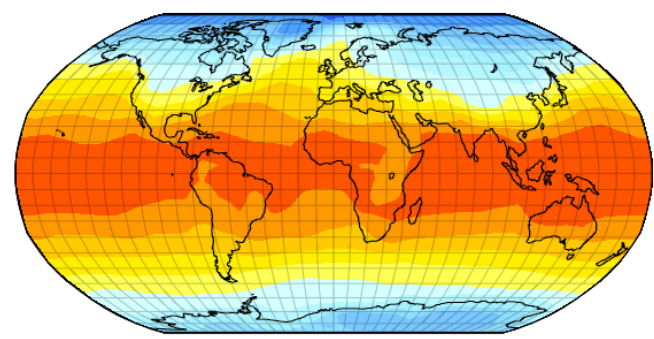

(c)

DecJanFeb Surface Air Temperature

$30^{\circ}$

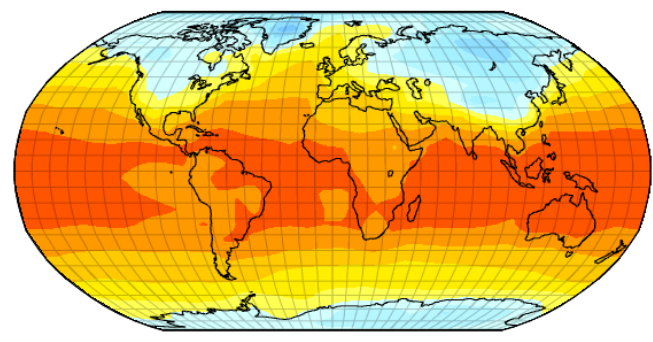

(d)

DecJanFeb Surface Air Temperature

$45^{\circ}$

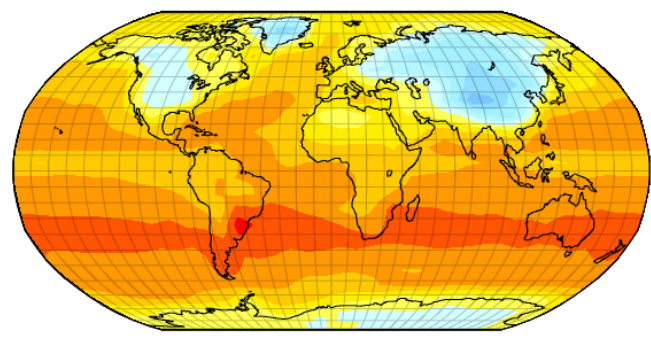

(e)

DecJanFeb Surface Air Temperature Control (Controle23,44.1940-201010.,nc)

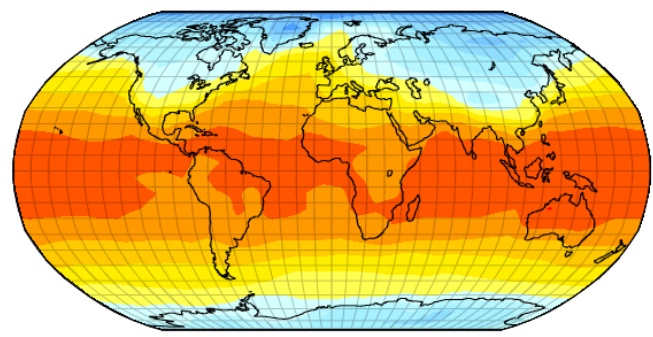

Surface Air Temperature (deg C)

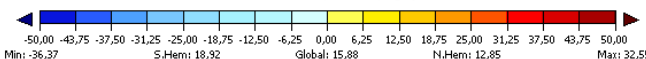

Figura 7. Similar à Figura 5, mas para o verão austral (dezembro-janeiro-fevereiro). (a) DecJanFeb SurfAirTemp

$0^{\circ}$

(Inclinacaozero. 1940-2010ij_Controle23.44.1940-2010ij_6345.ncdf)

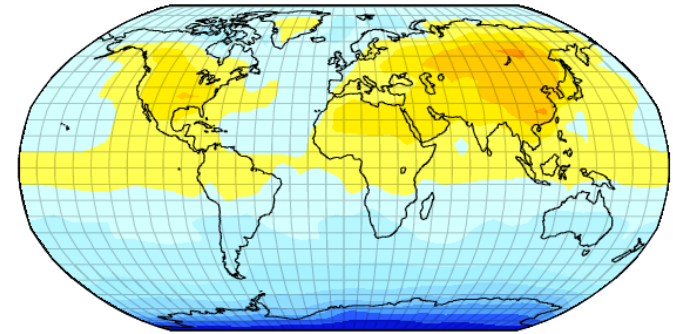

(b)

DecJanFeb SurfAirTemp

$15^{\circ}$

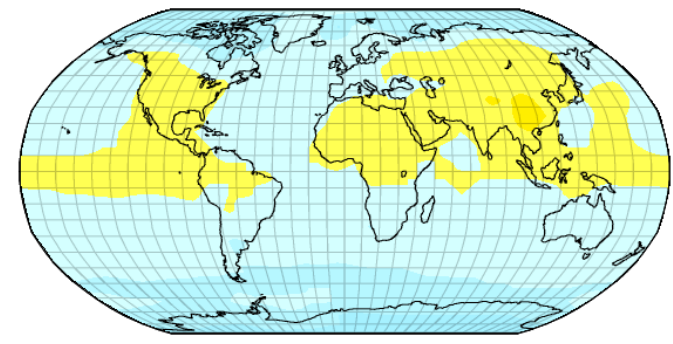

(c)

DecJanFeb SurfAirTemp

$30^{\circ}$

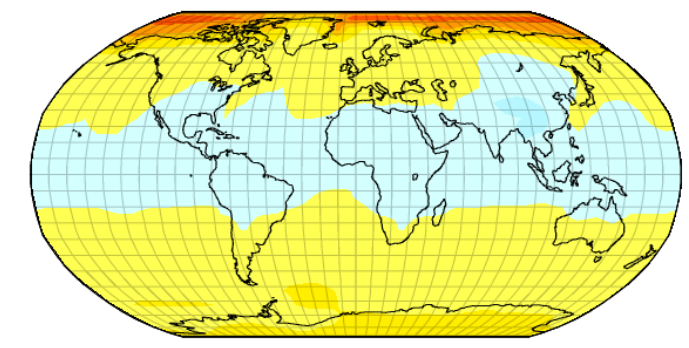

(d)

DecJanFeb SurfAirTemp

$45^{\circ}$

(Inclinacra045.1940-2010i__Controle23.44.1940-2010i__7003.ncdf)

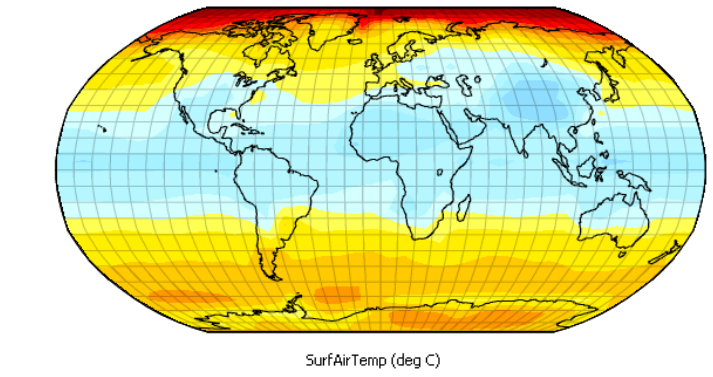

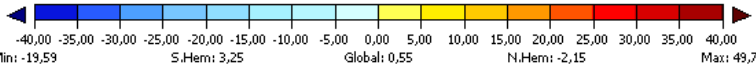

Figura 8. Similar à Figura 6, mas para o verão austral.

que no HN, mas as Fig.s 8 c-d mostram o contrário. Sugere-se que a topografia elevada da Antártida seja um dos principais responsáveis pelas menores diferenças de temperatura no polo sul. De fato, ao se analisar a faixa de intensas diferenças positivas de temperatura do ar no polo norte, verifica-se um setor com menores diferenças que corresponde à Groelândia, outro lugar com topografia elevada.

No inverno austral (junho-julho-agosto, Fig. 9), considerando-se o experimento que não há inclina- 
(a) JunJulAug Surface Air Temperature

$0^{\circ}$

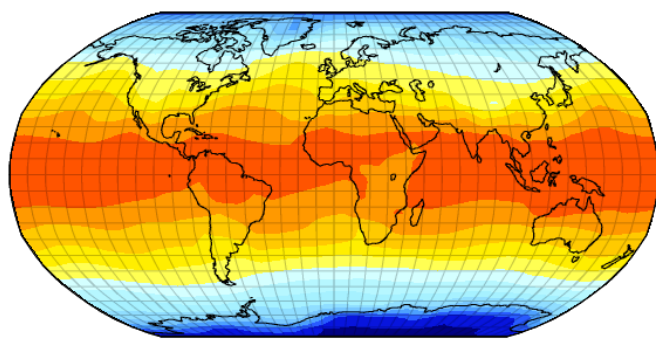

(b)

JunJulAug Surface Air Temperature (Inclinacao15.1940-2010ij.nc)

$15^{\circ}$

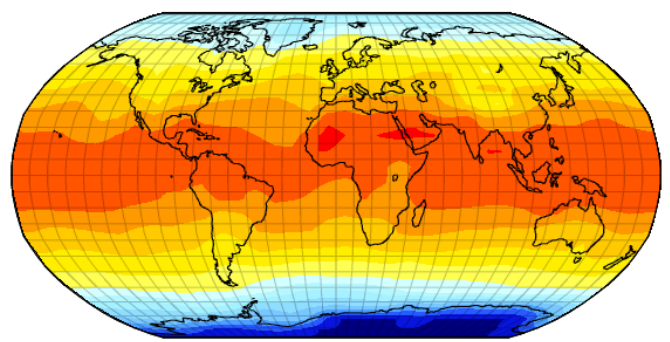

(c)

JunJulAug Surface Air Temperature

$30^{\circ}$

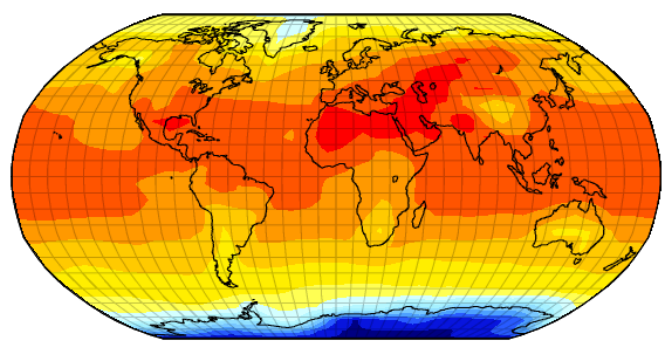

(d)

JunJulAug Surface Air Temperature

$45^{\circ}$

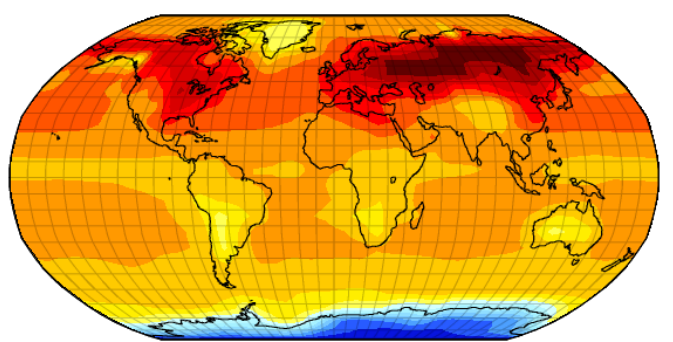

(e)

$$
\text { JunJulAug Surface Air Temperature Control }
$$

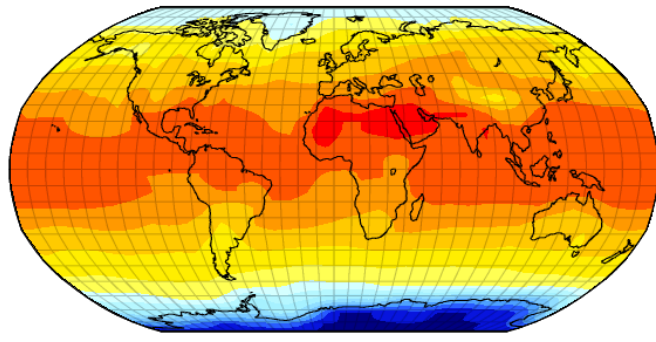

Surface Air Temperature (deg C)

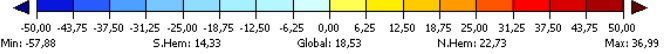

Figura 9. Similar à Figura 5, mas para o inverno austral (junho-julho-agosto). ção no eixo de rotação da Terra (Fig. 9a), observa-se o mesmo padrão espacial da temperatura do ar como na média anual (Fig. 5a) e verão austral (Fig. 7a), já que nesse experimento os raios solares não migram latitudinalmente ao longo do ano. Novamente, ressalta-se que em consequência da topografia elevada da Antártida as temperaturas são mais baixas nessa região em relação às latitudes correspondentes do HN. À medida que o ângulo de inclinação do eixo de rotação da Terra aumenta e é considerado o inverno austral, a banda de maior aquecimento migra para latitudes mais altas do HN, enquanto o HS torna-se mais frio (Figs. 9b-d). Um fato que deve ser levado em consideração em todas as simulações é a diferença de temperatura entre os oceanos e os continentes numa mesma banda de latitude. Quando é inverno num dado hemisfério, os continentes deste são, em geral, mais frios do que os oceanos na mesma latitude. Já no hemisfério que está ocorrendo o verão, os continentes são mais quentes do que os oceanos. Isso está associado à diferente capacidade térmica dos oceanos e continentes. Comparando-se as Fig.s 7 e 9, nota-se que as temperaturas no verão do HN (inverno do HS) são mais elevadas do que as temperaturas no verão do HS. Um fato associado a isso é a maior extensão da área continental do HN.

Comparando-se cada experimento com o controle no inverno austral (Fig. 10), observa-se que quando o ângulo de inclinação do eixo de rotação da Terra é menor do que no experimento controle, em geral, o HN é mais frio do que no experimento controle e o HS é mais quente, quando se consideram as regiões continentais (Figs. $10 \mathrm{a}-\mathrm{b}$ ). Já quando a obliquidade do planeta é maior do que no experimento controle, há diferenças positivas de temperatura nas latitudes médias e altas de ambos os hemisférios e negativas na região tropical (Figs. 10 c-d). É durante o inverno austral (que corresponde ao verão boreal) que as temperaturas atingem seus maiores valores sobre os continentes do HN, o que está associado ao solstício e também à capacidade térmica do continente de se aquecer rapidamente no verão boreal.

\section{Conclusões}

Esse estudo apresentou a definição dos parâmetros orbitais de Milankovitch (excentricidade da órbita terrestre, precessão e obliquidade do eixo de rotação da Terra) e como esses parâmetros influenciam o clima da Terra, bem como resultados 


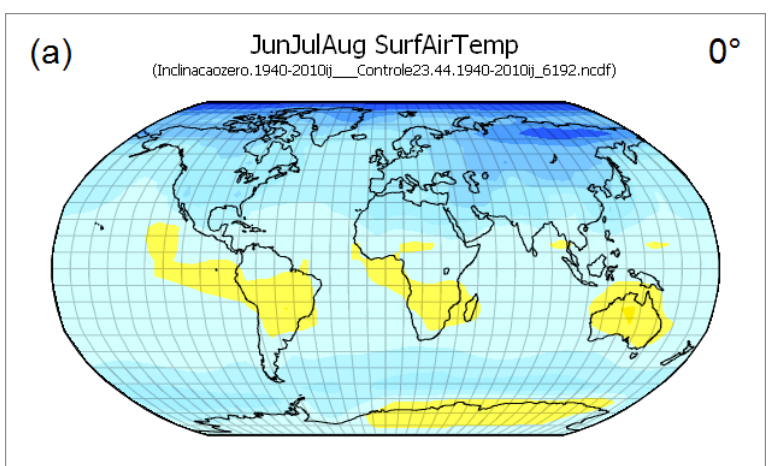

(b)

JunJulAug SurfAirTemp

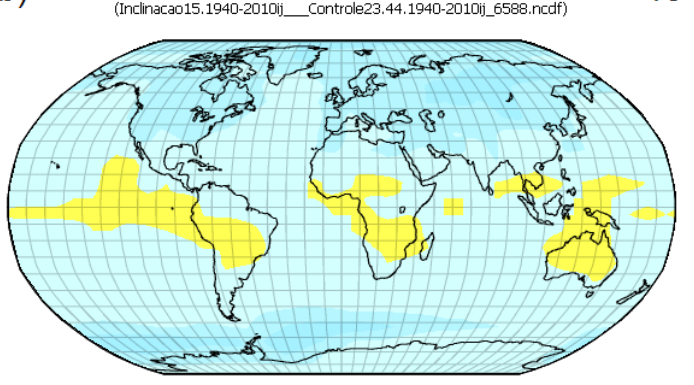

(c)

JunJulAug SurfAirTemp (inclinaca030.1940-2010ij__Controle23.44.1940-2010ij_6781.ncdf)

$30^{\circ}$

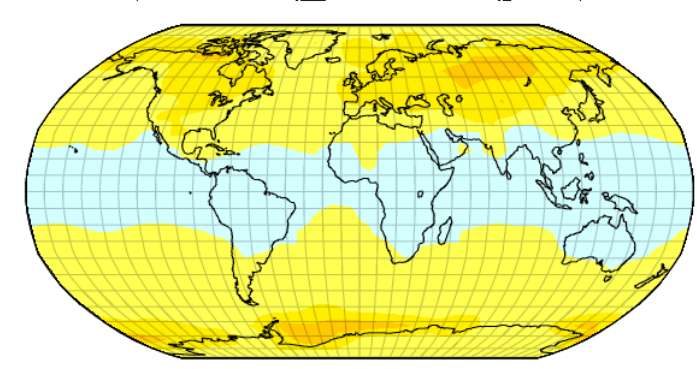

(d)

JunJulAug SurfAirTemp JunJulAug SurfAirTemp
(Inclinaca045.1940-2010ij__ontrole23.44.1940-2010ij_6962.ncdf)

$45^{\circ}$

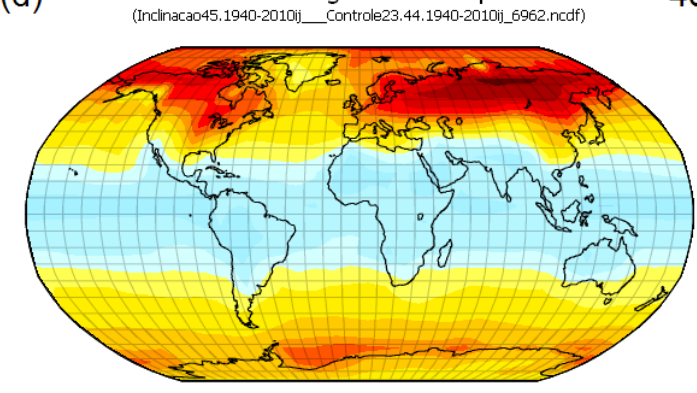

SurfairTemp (deg C)

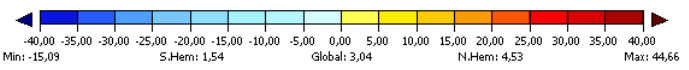

Figura 10. Similar à Figura 6, mas para o inverno austral.

de simulações numéricas obtidas com um modelo climático global de cunho educacional (EdGCM), em que o ângulo de inclinação do eixo de rotação da Terra foi alterado para valores menores e maiores do que o atual $\left(23,5^{\circ}\right)$. Através dessas simulações, foi mostrada a influência da obliquidade do planeta nos campos de temperatura do ar global.
Em termos gerais, considerando a ausência de obliquidade do eixo de rotação do planeta, a temperatura do ar é maior na região tropical e decresce em direção aos polos em ambos os hemisférios. Por outro lado, à medida que o ângulo de inclinação do eixo de rotação da Terra aumenta, há uma migração latitudinal, em direção aos polos, da zona de maior aquecimento, de forma que cada hemisfério experimenta um aquecimento máximo somente uma vez ao ano.

Quandoé computada a diferença da temperatura do ar dos experimentos de $30^{\circ}$ e $45^{\circ}$ em relação ao controle $\left(23,5^{\circ}\right)$, há diferenças positivas de temperatura em latitudes médias e altas de ambos os hemisférios (independentemente se é solstício de verão ou inverno) e diferenças negativas na região tropical. As diferenças negativas ocorrem devido ao menor tempo de insolação nos trópicos em tais condições de obliquidade, enquanto que as diferenças positivas são devido ao armazenamento de energia quando é verão em cada hemisfério. Como destacam Williams e Pollard (2003), o aquecimento no verão em ambos os hemisférios consegue manter a superfície e a atmosfera quente durante os meses escuros de inverno. Portanto, essa é a justificativa para as diferenças positivas de temperatura do ar, mesmo sendo inverno em um dos hemisférios.

Por fim, esse trabalho almeja servir de guia para estudos sobre as variações de temperatura do ar no planeta associadas com a obliquidade da Terra. Além disso, o trabalho abordou pontos importantes como: porque o HN é mais quente do que o HS, porque as temperaturas nas latitudes da Antártida são mais frias do que as suas correspondentes no $\mathrm{HN}$ e a diferença de aquecimento entre continentes e oceanos.

\section{Referências}

Ferreira D., Marshall J., O'Gorman P.A., Seager A. 2014. Climate at high-obliquity. Icarus, 243:236248.

Feulner G., Rahmstorf S., Levermann A., Volkwardt S. 2013. On the Origin of the Surface Air Temperature Difference between the Hemispheres in Earth's Present-Day Climate. J. Climate, 26:7136-7150.

Hansen J., Russell G., Rind D., Stone P., Lacis A., Lebedeff S., Ruedy R., Travis L. 1983. Efficient Three-Dimensional Global Models for Climate Studies: Models I and II. Monthly Weather Review, 111(4):609-662. 
Hartmann D.L. 1994. Global Physical Climatology. Academic Press, San Diego. (Intern. Geophysics Series).

Kang S.M., Seager R., Frierson D.M.W., Liu X. 2015. Croll revisited: Why is the northern hemisphere warmer than the southern hemisphere? Climate Dynamics, 44:1457-1472.

Laskar J., Robutel P. 1993. The chaotic obliquity of the planets. Nature, 361:608-612.

Moran J.M. 2012. Climate Studies. Introduction to Climate Sciences. Amer. Meteor. Soc. 525p.

Oliveira Filho K.O., Saraiva M.F.O. 2014. Astronomia e Astrofísica. Depto. Astronomia, Inst. Física, Univ. Fed. Rio Grande do Sul. URL: http://astro. if.ufrgs.br/livro.pdf. Acesso 03.05.2014.
Reboita M.S., Krusche N., Ambrizzi T., Rocha R.P.da. 2012. Entendendo o Tempo e o Clima na América do Sul. Terrae Didatica, 8(1):34-50.

Ruddiman W.F. 2008. Earth's Climate: Past and Future. New York: W.H. Freeman. 388p.

Spiegel D.S., Menou K., Scharf C.A. 2009. Habitable Climates: The Influence of Obliquity. The Astrophys. J., 691:596-610.

Ward W.R. 1974. Climatic variations of Mars: astronomical theory of insolation.J. Geophys. Res., 79: 3375-3386.

Williams D.M., Pollard D. 2003. Extraordinary climates of Earth-like planets: three-dimensional climate simulations at extreme obliquity. Intern. J. Astrobiol., 2:1-19.

RESUM0: 0 clima da Terra é controlado tanto por forçantes externas quanto internas ao sistema terrestre. Entre as forçantes externas têm-se os parâmetros orbitais de Milankovitch: excentricidade, precessão e obliquidade. Como a definição desses parâmetros e a influência deles no clima terrestre são abordadas de forma superficial nos livros-texto do ensino médio e até nos do superior, 0 presente estudo tem dois objetivos: (1) explicar cada parâmetro orbital de Milankovitch e como o clima da Terra é afetado por esses parâmetros e (2) avaliar, por meio de simulações numéricas, a influência do ângulo de inclinação do eixo de rotação da Terra na distribuição espacial e sazonal da temperatura do ar global. Entre os resultados, é mostrado que, quanto maior a obliquidade do eixo de rotação da Terra, a faixa de maior aquecimento durante o verão de um dado hemisfério se desloca para latitudes mais altas.

PALAVRAS-CHAVE: parâmetros orbitais de Milankovitch, Terra, simulações numéricas, clima 